\title{
20 jaar Verantwoordingsdag: Inzicht voor Kamercommissies
}

\author{
Hoe inhoudsanalyse inzicht geeft in prestatiegegevensgebruik \\ door Kamerleden*
}

Sjoerd Keulen

\begin{abstract}
De twintigste verjaardag van Verantwoordingsdag is een passend moment om de staat van de verantwoording te analyseren. Tien jaar geleden gold de dag nog als 'grandioos mislukt'. Dit artikel nuanceert dit. Uit inhoudsanalyse van debatten, vragen en moties van Nederlandse parlementariërs bij commissiebehandelingen van jaarverslagen blijkt dat zij systematisch prestatiegegevens gebruiken. Dit gebeurt tijdens alle onderdelen van verantwoordingsdebatten: informeren, debatteren en sanctioneren. Dit is tegengesteld aan de communis opinio uit de literatuur over het gebruik van prestatiegegevens door politici. Dit is te verklaren door de eerder gekozen onderzoeksmethoden. Het gebruik van prestatiegegevens is de afgelopen twintig jaar steeds toegenomen. In verantwoordingsdebatten blijken prestatiegegevens (jaarverslag, verantwoordingsonderzoek) veruit de meest geraadpleegde informatiebron voor Kamerleden. Dat parlementariërs prestatiegegevens cruciaal vinden, blijkt ook uit de versterking van het verantwoordingsforum. Echter, ondanks twintig jaar verbetering van verantwoording en Performancebased Budgeting menen Kamerleden nog steeds dat zij niet goed het geld kunnen volgen.
\end{abstract}

\section{Inleiding}

Dit jaar is de twintigste verjaardag van Verantwoordingsdag in de Tweede Kamer. Om het belang van verantwoording te benadrukken spiegelde men symboliek en ceremonieel van Prinsjesdag, zoals de op deze dag gepresenteerde jaarverslagen ook een spiegel zouden vormen van de begroting. Met Verantwoordingsdag werd een Performance-based budgetingsystematiek (VBTB - Van Beleidsbegroting tot Beleidsverantwoording en vanaf 2010 Verantwoord Begroten) geïntroduceerd om het inzicht in de prestaties van de rijksoverheid en de verantwoording te vergroten (De Jong, Van Beek, \& Posthumus, 2013; Van Nispen tot Pannerden \& Posseth, 2006). De verwachting dat in meeslepende debatten het kabinet de doeltreffendheid en doelmatigheid van het beleid zou verantwoorden, kwam niet uit. Bij gelegenheid van het eerste decennium concludeerden Bovens en Schillemans dat de dag 'grandioos mislukt' was (Bekkers 2009; Bovens \& Schillemans, 2009). In

* Dr. S.J. Keulen is onderzoeker bij de Algemene Rekenkamer en universitair docent Bestuurskunde aan de Erasmus Universiteit Rotterdam. 
latere terugblikken trokken journalisten en accountants dezelfde conclusies. Het debat ging eigenlijk nooit over verantwoording, maar vooral over de 'waan van de dag' (Geuze, 2014; Dijkstra, Rugenbrink, \& Telgenkamp, 2012).

Deze conclusies passen in een groeiende onderzoekslijn over waarom politici nauwelijks prestatiegegevens gebruiken in hun werk (Ter Bogt, Van Helden, \& Van der Kolk, 2015; Buylen \& Christiaens, 2016; Demaj \& Summermatter, 2012; Pollitt, 2006; Raudla, 2012). Dit werd in 2016 kernachtig samengevat door Moynihan (2016): 'Politicians do not use performance data.'

Toch is er ook bewijs dat politici wel degelijk actief prestatiegegevens gebruiken - bijvoorbeeld voor schriftelijke vragen (Van Dooren, 2004) - en deze rapportages nuttig vinden (Brun \& Siegel, 2006; George, Baekgaard, Decramer, Audenaert, \& Goeminne, 2018). Dit artikel bouwt verder op deze lijn en betoogt dat Tweede Kamerleden wel degelijk prestatiegegevens gebruiken in hun werk. Dit doen Kamerleden incrementeel; wie over de jaren terugkijkt, ziet een duidelijke toename, appreciatie en professionalisering van het gebruik van prestatiegegevens in woord en geschrift. Wie actief gebruik wil zien, moet zich richten op een tot nu toe vergeten aspect van Verantwoordingsdag: het beoordelen van de jaarverslagen en de dechargeverlening in de Vaste Kamercommissies.

Dit wordt als volgt betoogd: eerst presenteert het theoretisch kader Performancebased Budgeting, prestatiegegevens en een literatuuroverzicht van het gebruik van prestatiegegevens door parlementariërs. De operationalisatie introduceert het raamwerk voor verantwoording van Bovens (2007) en behandelt de onderzoekstechnieken. Het raamwerk van Bovens structureert vervolgens de bevindingen. De conclusie weegt tot slot de bewijzen tegen de bestaande literatuur en presenteert aanbevelingen voor vervolgonderzoek.

\section{Theorie: politici gebruiken geen prestatiegegevens}

Performance-based Budgeting (PBB) werd ingevoerd op de golven van New Public Management. Dit had gevolgen voor het begrotingsbeleid, dat zich nu ook sterker richtte op management, het behalen van resultaten en de verantwoording hiervan (Hood, 1995). Nederland behoorde met de introductie van VBTB in 1999 niet bepaald tot de koplopers van $\mathrm{PBB}$. Uit een literatuuroverzicht weten we dat het verbeteren van verantwoording een van de redenen is om $\mathrm{PBB}$ in te voeren (Mauro, Cinquini, \& Grossi, 2017). Het initiatief om PBB in te voeren, komt doorgaans vanuit de overheidsorganisatie en niet vanuit het parlement (Clark, Menifield, \& Stewart, 2018). Dit blijkt ook uit het gedrag van parlementariërs. Alhoewel de aangeleverde informatie en de functie van de begroting veranderen, blijft de relatie tussen parlement en regering ongewijzigd. Opvallend is eveneens dat er geen studies bekend zijn die aantonen dat de verwachte voordelen ook daadwerkelijk gerealiseerd zijn (Mauro et al., 2017).

Prestatiegegevens behoren de drijvende kracht van Performance Budgeting te zijn. Prestatiegegevens zijn te definiëren als informatie, vaak in de vorm van prestatie-indicatoren over doeltreffendheid, effectiviteit en doelmatigheid (Van Dooren, Bouckaert, \& Halligan, 2015). De basisgedachte achter prestatiegegevens 
is dat door terug te kijken op prestaties, deze in de toekomst te verbeteren zijn (Nielsen, 2014; Behn, 2003).

Echter, of prestatiegegevens ook daadwerkelijk gebruikt worden, blijft de 'big question' op de onderzoeksagenda (Moynihan \& Pandey, 2010). Daarom is Verantwoordingsdag, een centraal moment waarin de verantwoording van deze prestatiegegevens centraal hoort te staan, een goede ingang om het daadwerkelijke gebruik van deze gegevens te onderzoeken. Temeer omdat in vergelijking met de literatuur over het gebruik van prestatiegegevens door managers het gebrek aan literatuur over gebruik door politici opvallend is. Studies over het gebruik van prestatiegegevens door politici schetsen een somber beeld. In een literatuurstudie uit 2012 concludeerden Demaj en Summermatter dat politici prestatiegegevensrapporten niet lezen en hun informatie voornamelijk krijgen door met hoge ambtenaren of collega's te praten. Wel werden prestatiegegevens vaker gebruikt als het politieke systeem dit accommodeerde. Dit was met name het geval als prestatiegegevens geloofwaardig werden geacht en als er sterke pleitbezorgers waren.

Uit literatuur over prestatiegegevensgebruik door parlementariërs blijkt dat er nauwelijks bewijs is dat parlementariërs deze informatie gebruiken. De OESO rapporteerde in 2005 dat slechts in 19\% van de lidstaten parlementariërs prestatiegegevens gebruikten. Opvallend genoeg was dat gebruik in begrotingscommissies zelfs nog lager (Curristine, 2005). Vervolgonderzoek bevestigde dat er weinig bewijs is dat parlementariërs prestatiegegevens gebruiken (Sterck, 2007, p. 200). Eenzelfde conclusie trok Pollitt (2005). Uit onderzoek naar deelstaatsparlementen in de Verenigde Staten bleek hetzelfde. Alhoewel in vrijwel alle staten PBB was ingevoerd, werd begrotingsinformatie nauwelijks gebruikt in debatten of in besluitvorming (Ingraham, 2005; Hou, Lunsford, Sides, \& Jones, 2011). Dit maakt de Nederlandse casus van Verantwoordingsdag ook internationaal interessant, in vergelijkbare verantwoordingsmomenten werden prestatiegegevens immers nauwelijks gebruikt.

Uit kwalitatieve studies naar prestatiegegevensgebruik door parlementariërs weten we dat tijdgebrek de belangrijkste reden is om prestatiegegevens niet te lezen (Raudla, 2012). Tien pagina's geldt als maximum voor een rapportage om gelezen te worden (Brun \& Siegel, 2006). Twijfel over de betrouwbaarheid van de rapportages en het nut van de rapportages is een andere verklaring om prestatiegegevens ongelezen te laten. Grote uitzondering hierop vormen de rapportages van equivalenten van de Algemene Rekenkamer, die wel als behulpzaam en betrouwbaar worden gezien (Johnson \& Talbot, 2008). De studie van Van Dooren (2004) betoogde als een van de weinige studies dat parlementariërs wel degelijk prestatiegegevens gebruiken. Uit zijn inhoudsanalyse bleek dat $52 \%$ van de vragen van Vlaamse parlementariërs prestatiegegevens bevatten.

Verschillende onderzoekers wijzen erop dat enquêteonderzoek het prestatiegegevensgebruik door politici te hoog inschat (Raudla, 2012; Bourdeaux, 2008; Van Helden, 2016); onderzoeken op basis van interviews laten een meer realistisch beeld zien van niet-gebruik. Dit werd bevestigd door Ter Bogt et al. (2015), die beide methoden combineerden. Van het hoge gebruik uit de zelfrapportage bleef in de observatiestudie nauwelijks iets over. Zowel interviews als observatiestudies hebben belangrijke nadelen. Het brein is goed in vergeten, zeker van onspecifieke 
of niet-bepalende herinneringen, zoals het gebruik van prestatiegegevens in het dagelijks werk (Draaisma, 2015; Murre \& Dros, 2015). Observaties kunnen het gebruik weliswaar goed registreren, maar zijn duur en meestal beperkt van omvang. Inhoudsanalyse heeft deze nadelen niet en hiervan is bewezen dat het prestatiegegevensgebruik kan vaststellen (Buylen \& Christiaens, 2016; Van Dooren, 2004; Johnson \& Talbot, 2008). Hierdoor weten we dat woordgebruik in debatten gezien mogen worden als specifiek gebruik van financiële en prestatieinformatie. Dit geeft meer direct bewijs voor prestatiegegevensgebruik dan interviews of enquêtes (Buylen \& Christiaens, 2016; Imbeau, 2009).

\section{Operationalisatie}

Dit artikel is gestructureerd met behulp van de stadia van verantwoording van Bovens (2007). Bovens definieerde verantwoording als een relatie tussen een actor en een forum, waarin de actor verplicht is om zijn gedrag te verklaren en te rechtvaardigen en waarbij het forum vragen kan stellen en de actor kan beoordelen. Deze relatie doorloopt drie stadia die ook in het Nederlands parlement zichtbaar zijn. In de eerste fase informeert de actor het forum door informatie te leveren: hier de jaarverslagen. In de tweede fase kan het forum de actor ondervragen in een debat. De derde fase is de beoordeling. De Tweede Kamer gebruikt hiervoor twee sanctiemechanismen: de moties en het onthouden van decharge (Andeweg \& Irwin, 2014).

Door inhoudsanalyse kunnen we kijken of er tijdens de verschillende stadia prestatiegegevens gebruikt worden (Bourdeaux, 2008; Frank \& D’Souza, 2004; Raudla, 2012; Van Helden, 2016). Door over een lange periode te kijken kunnen we onderzoeken of het verantwoordingsproces zich door de jaren heen versterkt heeft (Nielsen, 2014). Om dit te kunnen doen zijn verschillende technieken nodig. De ontwikkeling van het forum zal worden onderzocht door de ontwikkelingsgeschiedenis van Kamerprocedures te bekijken. Dit is gedaan met behulp van een literatuurstudie van de Handelingen en Kamerstukken, specifiek de jaarlijkse evaluatie van de begrotingscyclus van de commissie voor de Rijksuitgaven.

De stadia van informeren en debatteren zijn bekeken door allereerst het aantal schriftelijke vragen per commissie te tellen. Een toename in het aantal vragen is een eerste indicatie dat prestatiegegevens (vaker) gebruikt worden (Van Dooren, 2004). Om te bekijken of prestatiegegevens gebruikt worden, zijn debatten van twee commissies geselecteerd, waarvan één behandelmethoden initieerde die door andere commissies werden overgenomen (Johnson \& Talbot, 2008).

Het stadium van sanctioneren wordt onderzocht door te kijken naar het aantal moties en weigering van decharge. Hierbij is onderzocht of de inhoud van de moties over prestatiegegevens gaat (Van Dooren, 2004). Door de aangenomen moties over prestatiegegevens af te zetten tegen andere moties kunnen we het relatieve belang van prestatiegegevens voor Kamerleden vaststellen. 


\section{De versterking van het forum}

In de afgelopen twintig jaar hebben zich in de debatten van de Kamercommissies over de jaarverslagen vier belangrijke veranderingen voorgedaan. Allereerst werden in 2006 technische briefings door de Algemene Rekenkamer geïntroduceerd waarin Kamerleden vragen aan de Rekenkamer kunnen stellen over het jaarverslag of het verantwoordingsonderzoek (Kamerstuk II 2007/8, 31 212, nr. 1). Twee jaar later werkten alle Kamercommissies met deze briefing. Na de technische briefing en beantwoording van de schriftelijke vragen wordt steeds vaker een wetgevingsoverleg (een commissiedebat met de minister) ingepland. Toen in 2010 Verantwoord Begroten werd geïntroduceerd, hield slechts de helft van de commissies zo'n debat, nu doen met uitzondering van de commissie Financiën alle commissies dit (Kamerstuk II 2016/17, 31 865, nr. 10, appendix 3).

In 2006 werd ook een tweede noviteit ingevoerd, de rapporteur. Bijna alle commissies benoemden uit hun midden een rapporteur die de kwaliteit van het jaarverslag moest beoordelen. Uit evaluatie van de Kamer bleek dat hierdoor de aandacht voor de kwaliteit van het jaarverslag toenam en bewindslieden vaker toezegden de kwaliteit te gaan verbeteren (Kamerstuk II 2007/8, 31 212, nr. 1, p. 13). Het succes hield echter niet lang aan. In 2011 had nog maar één commissie een rapporteur. Een jaar later werd een nieuw rapporteurssysteem ingevoerd: het systeem-Duisenberg (Duisenberg, 2016). Hierin werken een lid van de oppositie en de coalitie samen om alle doelen en beloften te bekijken en zetten zij deze om in een overzichtelijk stoplichtsysteem. Dit zou de informatiepositie verbeteren, de controle verdiepen en een langetermijnperspectief bieden. Door rapporteurs 'voorkom je dat ieder individueel Kamerlid zelf elk jaar met al die dikke dossiers voor z'n neus gaat zitten en er iets willekeurigs uitpikt om op te schieten' (De Wit Wijnen, 2015). Dit nieuwe rapporteurschap werd snel overgenomen door andere commissies; in 2017 werkten acht van de elf commissies met dit systeem. Het vond ook zijn weg buiten de Kamer naar provincies, steden en in aanbevelingen van de Vereniging Nederlandse Gemeenten.

\section{Informeren: Steeds meer vragen over verantwoordingsinformatie}

Het stadium van informeren heeft zich door de tijd heen sterk ontwikkeld. In het eerste jaar stelden Kamerleden 900 verschillende schriftelijke vragen over de jaarverslagen. Dit aantal bleef het eerste decennium stabiel en schommelde tussen de 900 en de 1.100 vragen. Na de introductie van Verantwoord Begroten steeg dit aantal snel: van 200 vragen in 2010 tot 2.068 vragen in 2017.

Om deze cijfers in een context te plaatsen kunnen ze worden afgezet tegen de twee vormen van schriftelijke vragen die de Kamer gebruikt. Er zijn de lijsten van vragen die worden gebruikt als eerste stap in een wetsbehandeling en er zijn de individuele schriftelijke vragen, veelal naar aanleiding van een nieuwsbericht. Beide vraaginstrumenten groeiden niet zo snel. De lijsten van vragen zijn vrijwel stabiel gebleven sinds 2005, het aantal lijsten week nooit meer dan $30 \%$ af van het basisjaar 2005. Het aantal individuele schriftelijke vragen bleef eveneens 
Tabel 1 Vergelijking schriftelijke vragen, 2000-2017

\begin{tabular}{lccc}
\hline Jaar & $\begin{array}{c}\text { Schriftelijke vragen } \\
\text { over jaarverslagen }\end{array}$ & $\begin{array}{c}\text { Individuele schriftelijke } \\
\text { vragen }\end{array}$ & Aantal vragenlijsten \\
\hline 2000 & 932 & & \\
2001 & 1259 & & \\
2002 & 920 & & \\
2003 & 850 & 2045 & 262 \\
2004 & 1071 & 1772 & 246 \\
2005 & 838 & $267 \mid$ & 266 \\
2006 & 914 & 3002 & 320 \\
2007 & 1266 & 3029 & 341 \\
2008 & 1195 & 2552 & 249 \\
2009 & 1635 & 3057 & 298 \\
2010 & 200 & 2535 & 269 \\
2011 & 1136 & 2562 & 286 \\
2012 & 1163 & 2423 & 298 \\
2013 & 1163 & 2822 & 298 \\
2014 & 1177 & 2627 & 201 \\
2015 & 1289 & 2122 & \\
2016 & 1572 & & \\
2017 & 2068 & & \\
\hline
\end{tabular}

Bron: eigen telling van Kamerstukken II; Tweede Kamer, 20I0, 20I5, 2017

tamelijk stabiel tussen 2005 en 2017. Afgezet tegenover de sterke groei van het aantal vragen over de jaarverslagen is de toename van schriftelijke vragen over het jaarverslag opvallend.

Daarom kunnen we in ieder geval concluderen dat het gebruik van prestatiegegevens is toegenomen vanaf 2010. Men moet immers eerst de jaarverslagen lezen voordat er vragen over gesteld kunnen worden. Dit is in lijn met de bevindingen over het Vlaamse parlement (Van Dooren, 2004).

\section{Debatteren: prestatiegegevens in de hoofdrol}

Om te onderzoeken hoe prestatiegegevens door Kamerleden gebruikt worden in debatten, zijn vier debatten van twee Kamercommissies onderzocht. De commissie voor Onderwijs is gekozen omdat zij vooroploopt in het gebruik van prestatiegegevens, terwijl de commissie voor Justitie hierin terughoudend is. Beide commissies omvatten zo het hele spectrum van prestatiegegevensgebruik door de Kamer. Met een interval van vier jaar zijn vier debatten geanalyseerd, zodat er een langetermijnperspectief op prestatiegegevensgebruik ontstaat. Op basis van 
Tabel 2 Wetgevingsdebatten over het jaarverslag commissie van Veiligheid en Justitie

\begin{tabular}{lrrrr}
\hline Jaar & $\mathbf{2 0 0 4}$ & $\mathbf{2 0 0 8}$ & $\mathbf{2 0 ~ I 2 ~}$ & $\mathbf{2 0 ~ I 6 ~}$ \\
\hline $\begin{array}{l}\text { Aantal schriftelijke vragen (waarvan } \\
\text { over de rapportage van de Algemene }\end{array}$ & $95(4)$ & $154(20)$ & $242(100)$ & $234(64)$ \\
Rekenkamer) & & & & \\
Gebruik 'indicator' in het debat & 0 & 7 & 4 & 66 \\
Aantal moties & $\mathrm{I}$ & $\mathrm{I}$ & 3 & 2 \\
Lengte van het debat & $\mathrm{Iu} \mathrm{50m}$ & $2 \mathrm{u} 3 \mathrm{Im}$ & $2 \mathrm{u} 20 \mathrm{~m}$ & $\mathrm{Iu} 56 \mathrm{~m}$ \\
Aantal partijen aanwezig & $5(56 \%)$ & $5(50 \%)$ & $5(45 \%)$ & $5(42 \%)$ \\
Rapporteur & Nee & Nee & Nee & Nee \\
Technische briefing & Nee & Nee & Ja & Ja \\
\hline
\end{tabular}

Bronnen: Kamerstukken II

Tabel 3 Wetgevingsdebatten over het jaarverslag commissie van Onderwijs

\begin{tabular}{lrrrr}
\hline Jaar & $\mathbf{2 0 0 4}$ & $\mathbf{2 0 0 8}$ & $\mathbf{2 0 I 2}$ & $\mathbf{2 0 1 6}$ \\
\hline Aantal schriftelijke vragen (waarvan & $45(33)$ & $123(9)$ & $145(32)$ & $210(135)$ \\
$\begin{array}{l}\text { over de rapportage van de Algemene } \\
\text { Rekenkamer) }\end{array}$ & & & & \\
Aantal moties & 0 & 1 & 2 & 4 \\
Gebruik 'indicator' in het debat & 2 & 2 & 2 & 0 \\
Lengte van het debat & $1 \mathrm{u} 40 \mathrm{~m}$ & $2 \mathrm{u} \mathrm{Im}$ & $3 \mathrm{u} 5 \mathrm{~m}$ & $3 \mathrm{u} 55 \mathrm{~m}$ \\
Aantal partijen aanwezig & $6(67 \%)$ & $6(60 \%)$ & $9(81 \%)$ & $8(67 \%)$ \\
Rapporteur & Nee & $\mathrm{Ja}$ & $\mathrm{Ja}$ & $\mathrm{Ja}$ \\
Technische briefing & Nee & Nee & $\mathrm{Ja}$ & $\mathrm{Ja}$ \\
\hline
\end{tabular}

Bronnen: Kamerstukken II

de bekende kenmerken uit de tussenliggende jaren, zoals aantal schriftelijke vragen en de ontwikkeling van het rapporteurschap en de technische briefing, is er vertrouwen dat de onderzochte jaren een representatief beeld geven.

Uit de tabellen blijkt dat in beide commissies het aantal schriftelijke vragen en de duur van het debat toenamen, al geldt dit sterker voor de commissie van Onderwijs. De toegenomen lengte van het debat van deze commissie is te verklaren door het gebruik van de rapporteur. De geuite verwachting dat het rapporteurschap de debatten zou verdiepen (Kamerstuk II 2008/9, 31924 VIII, nr. 10) kwam niet uit. Na dankzegging door de commissie werden er nooit vervolgvragen door andere leden aan de minister gesteld (bijvoorbeeld Kamerstuk II 2012/13, 33605 VIII, nr. 2; Kamerstuk II 2016/17, 34725 VIII, nr. 14). Hetzelfde geldt voor de schriftelijke vragen: in geen van de commissies werden deze aangehaald tijdens het debat. 
Dat betekent niet dat Kamerleden prestatiegegevens niet belangrijk vinden. Een constante in alle debatten is de kritiek op het gebrek aan inzichtelijke prestatieindicatoren, kwantificeerbare doelen en ontbrekende output- en outcome-gegevens. Steeds benadrukken Kamerleden dat ze deze gegevens nodig hebben om hun taak goed te kunnen uitvoeren. Daarom ging de commissie voor Onderwijs ertoe over om samen met de minister nieuwe prestatie-indicatoren te ontwikkelen (Kamerstuk II 2012/13, 33605 VIII, nr. 13). Prestatie-indicatoren spelen in deze commissie over de jaren heen een duidelijkere rol in het debat dan bij de commissie voor Justitie.

In de debatten spelen prestatiegegevens de hoofdrol. Vrijwel alle vragen van de Kamerleden aan de minister zijn gebaseerd op het jaarverslag en nog vaker op het bijbehorende verantwoordingsonderzoek van de Rekenkamer. Vrijwel alle Kamerleden baseren hun vragen op de belangrijkste bevindingen van de Rekenkamer. Aan andere bronnen, zoals krantenberichten, gesprekken of rapporten, wordt nauwelijks gerefereerd. Opvallend is dat in de laatste jaren steeds vaker naar de opvolging van de bevindingen van de Rekenkamer van vorig jaar wordt gevraagd. Ondanks de vergrote aandacht en het intensieve gebruik van prestatiegegevens door de Kamerleden betekende dit niet dat de verantwoordingsinformatie elk jaar beter werd. In 2004 en 2008 is er fikse kritiek van de Algemene Rekenkamer op het gebrek aan inzicht in de prestaties en meetbare doelen, die in de jaren erna verstomt. Dat betekent echter niet dat Kamerleden zich voldoende geïnformeerd voelen. Zo weigerde de oppositie (28\% van de stemmen) in 2012 decharge te verlenen aan de minister van Justitie omdat deze volgens de Rekenkamer niet in control' was bij het opstellen van de jaarrekening (Kamerstuk II 2012/13, 33605 VI, nr. 12). Terwijl de commissie voor Onderwijs ondanks de rapporteurs en het meebepalen van prestatie-indicatoren in 2017 nog vaststelde: 'De Kamer kan nog steeds onvoldoende zien waar het geld is. De conclusie is dat de Kamer haar controlerende taak daardoor niet goed kan uitvoeren' (Kamerstuk II 2016/17, 34725 VIII, nr. 14, p. 4).

\section{Sancties: moties vaker ingezet}

De Tweede Kamer heeft voor het beoordelen van het jaarverslag twee sanctiemechanismen: de motie en het niet verlenen van decharge. Jaarverslagen zijn geen wetten en kunnen daarom niet worden geamendeerd.

$\mathrm{Al}$ in het tweede jaar van Verantwoordingsdag werd er een motie ingediend; twee jaar later gebeurde dit ook tijdens een commissiebehandeling (Kamerstuk II 2005/6, 30 529, nr. 1). Sindsdien is het aantal moties snel toegenomen. Tot en met 2017 werden er in totaal 404 moties in stemming gebracht. Het aantal ingediende moties tijdens Verantwoordingsdag en de commissiebehandeling groeide veel sneller dan andere moties. Tussen 2005 en 2017 verdubbelde het totale aantal moties, terwijl het aantal verantwoordingsmoties vertwintigvoudigde. 39\% van deze verantwoordingsmoties werd aangenomen, dit is iets vaker dan gemiddeld (32\% tussen 2006-2017) (Tweede Kamer 2015, 2017). 
Als we de verantwoordingsmoties inhoudelijk uitsplitsen naar politieke moties en moties die over prestatiegegevens gaan, zien we een interessant verschil. In totaal werd $67 \%$ van de moties over prestatiegegevens aangenomen $(70 \%$ in commissies, $63 \%$ tijdens Verantwoordingsdag). Dit is meer dan twee keer zo vaak als de gemiddelde motie. Interessant is verder dat moties over politieke onderwerpen tijdens de behandeling van verantwoordingsinformatie juist minder vaak aanvaard worden, gemiddeld haalt slechts $27 \%$ een meerderheid, tijdens het Verantwoordingsdebat is dit zelfs slechts $21 \%$.

Het tweede sanctiemechanisme - de weigering om decharge te verlenen - is het zwaarste sanctiemechanisme als jaarverslagen worden besproken. Het verkrijgen van decharge is een wettelijke verplichting (Comptabiliteitswet 2018: artikel 2.40). Normaliter is dit een formaliteit, slechts één keer, in 1995, is de dechargeverlening opgeschort (Tweede Kamer, 2009). De weigering van de oppositiepartijen om de minister decharge te verlenen over het jaar 2012 is daarmee zeer ongebruikelijk. Het weigeren van decharge wordt uitgelegd als een motie van wantrouwen (Ringe, 2005).

\section{Conclusie}

In het artikel is aangetoond dat inhoudsanalyse een goed middel is om daadwerkelijk prestatiegegevensgebruik door politici vast te stellen. Zowel in de fases van informeren en debatteren als sanctioneren is het duidelijk dat politici prestatiegegevens in de vorm van jaarverslagen en verantwoordingsonderzoek daadwerkelijk lezen en gebruiken. Dit is duidelijk een andere conclusie dan eerder onderzoek naar het gebruik van prestatiegegevens door politici laat zien (Moynihan, 2016; Demaj \& Summermatter, 2012; Raudla, 2012; Johnson \& Talbot, 2008). Het daadwerkelijk gebruik was af te lezen uit de schriftelijke vragen over prestatiegegevens, uit het aanhalen van prestatie-indicatoren of bevindingen van de Rekenkamer in debatten of uit de bewoording van de ingediende moties. In alle drie de gevallen neemt het prestatiegegevensgebruik door de jaren alleen maar toe. De hiervoor gebruikte prestatierapporten zijn veel langer dan de leesgrens van tien pagina's (Brun \& Siegel, 2006). De jaarlijkse toename van vragen en moties en het consequent gebruik van deze informatie in debatten laten bovendien zien dat dit het gebruik systematisch is. Dat prestatiegegevens belangrijk worden geacht, blijkt uit de versterking van het forum, de inhoud van de debatten en de hoge instemmingspercentages van moties over prestatiegegevens.

Geholpen door de recente aandacht voor rapporteurs en de 'methode-Duisenberg' ontstaat ook op gemeente- en provincieniveau meer aandacht voor verantwoording op basis van prestatiegegevens. Hierbij worden ook steeds vaker instellingen (Almere) en burgers (Tweede Kamer) betrokken. Op basis van dit onderzoek is die trend toe te juichen. Dit artikel leert dat voor een succesvolle verantwoording de basisvoorwaarden in orde moeten zijn. Deels zijn die al aanwezig; zo wordt Performance-based Budgeting al sinds 2003 gebruikt door provincies en gemeenten. Een versterkt forum is een tweede basisvoorwaarde. Rapporteurs kunnen daarvoor een hulpmiddel zijn, net als ondersteuning door onafhankelijke 
deskundigen. Lokale en provinciale rekenkamers of de accountant zouden hier een grotere rol kunnen spelen. Om verantwoording werkelijk effectief te maken moet tot slot ook goed over het sanctie-instrument worden nagedacht.

Verandering in de stadia van de verantwoording is echter niet voldoende. Dit artikel laat vooral zien dat verantwoording een proces van de lange adem is en dat verandering van verantwoordingsinformatie met vallen en opstaan gaat. De toename van het aantal Kamervragen over prestatiegegevens voltrok zich immers langzaam en ondanks grote parlementaire betrokkenheid bij het opstellen van indicatoren blijven financiële stromen lastig te volgen. Daarmee is een waarschuwing voor hooggespannen verwachtingen op zijn plaats. Niet voor niets werd Verantwoordingsdag al snel als mislukt op de mestvaalt geworpen. Bovendien laat dit artikel zien dat vernieuwing en verbetering soms plaatsvindt op andere plaatsen dan verwacht: niet in het plenaire debat maar in de rust van de commissies.

Het vergroten van betrokkenheid onder politici voor verantwoording biedt kansen. Contrair aan Mauro et al. (2017) tonen de Nederlandse parlementariërs zich immers zeer geïnteresseerd in de ontwikkeling van PBB en hielpen ze zelfs mee om bruikbare prestatie-indicatoren op te stellen. Nader onderzoek zal moeten uitwijzen of deze interesse voortkomt uit de technische politieke cultuur van Nederland, waar de tendens sterk is om begrotingsbeleid, indicatoren en statistiek als iets niet-politieks te zien (Keulen, 2014). Door het gebruik van internationale verantwoordingsdebatten is dan ook vast te stellen of dit hogere gebruik van prestatiegegevens internationaal zichtbaar is.

Verder onderzoek zal ook de vraag moeten beantwoorden waarom ondanks de constante toename van schriftelijke vragen de antwoorden in de debatten geen rol spelen. Dit is gerelateerd aan de 'big question' (Moynihan \& Pandey, 2010) waarom men prestatiegegevens zou willen gebruiken, want waarom zou je vragen stellen als je de antwoorden niet actief gebruikt? Wat tot slot om onderzoek vraagt, is hoe het kan dat na twintig jaar Performance-based Budgeting en ondanks een constante toename van aandacht voor prestatiegegevens parlementariërs nog steeds menen dat ze 'het geld niet kunnen volgen' en daarmee hun taak niet goed kunnen uitvoeren. Daarom blijft het de vraag of PBB wel in staat is om de beloftes voor het verbeteren van effectiviteit van besluitvorming en verantwoording daadwerkelijk in te lossen.

\section{Literatuur}

Andeweg, R.B., \& Irwin, G.A. (2014). Governance and politics of the Netherlands. Basingstoke: Palgrave.

Behn, R.D. (2003). Why measure performance? Different purposes require different measures. Public aAdministration Review, 63(5), 586-606.

Bekkers, H. (2009). Verantwoordingsdag grandioos mislukt. Binnenlands Bestuur, 20(15), 8-11.

Bogt, H. ter, Helden, J. van, \& Kolk, B. van der. (2015). Challenging the NPM ideas about performance management: Selectivity and differentiation in Outcome-Oriented performance budgeting. Financial Accountability \& Management, 31(3), 287-315. 
Bourdeaux, C. (2008). Integrating performance information into legislative budget processes. Public Performance \& Management Review, 31(4), 547-569.

Bovens, M. (2007). The concept of public accountability. In E. Ferlie, L.E. Lynn, \& C. Pollitt (Eds.), The Oxford handbook of public management (pp. 182-208). Oxford: Oxford University Press.

Bovens, M., \& Schillemans, T. (2009). Handboek publieke verantwoording. Den Haag: Lemma.

Brun, M.E., \& Philipp Siegel, J. (2006). What does appropriate performance reporting for political decision makers require? Empirical evidence from Switzerland. International Journal of Productivity and Performance Management, 55(6), 480-497.

Buylen, B., \& Christiaens, J. (2016). Talking numbers? Analyzing the presence of financial information in councilors' speech during the budget debate in Flemish municipal councils. International Public Management Journal, 19(4), 453-475.

Clark, C., Menifield, C.E., \& Stewart, L.M. (2018). Policy diffusion and performance-based budgeting. International Journal of Public Administration, 41(7), 528-534.

Curristine, T. (2005). Government performance. OECD Journal on Budgeting, 5(1), 127-151.

Demaj, L., \& Summermatter, L. (2012). What should we know about politicians' performance information need and use? International Public Management Review, 13(2), 85-111.

Dijkstra, A., Rugenbrink, G., \& Telgenkamp, M. (2011). Verantwoordingsdag mist zijn doel. TPC - Tijdschrift voor Public Governance Audit en Control, 9(4), 42.

Draaisma, D. (2015). Forgetting: Myths, perils and compensations. Yale University Press.

Duisenberg, P. (2016). New development: How MPs in the Dutch parliament strengthened their budgetary and accounting powers. Public Money \& Management, 36(7), 521-526, doi:10.1080/09540962.2016.1237153

Frank, H. A., \& D’Souza, J. (2004). Twelve years into the performance measurement revolution: Where we need to go in implementation research. International Journal of Public Administration, 27(8-9), 701-718.

George, B., Baekgaard, M., Decramer, A., Audenaert, M., \& Goeminne, S. (2018). Institutional isomorphism, negativity bias and performance information use by politicians: A survey experiment. Public Administration, doi: https://doi.org/10.1111/padm.12390

Geuze, S. (2014). Wat zijn de beloftes van gehaktdag waard? Vijftien jaar verantwoordingsdebat in de Tweede Kamer. In C. van Baalen et al. (red.), Het geld regeert: Jaarboek parlementaire geschiedenis, 2014 (pp. 95-105). Amsterdam: Boom.

Helden, J. van. (2016). Literature review and challenging research agenda on politicians use of accounting information. Public Money \& Management, 36(7), 531-538.

Hood, C. (1995). The 'New public management' in the 1980s: Variations on a theme. Accounting, Organizations and Society, 20(2-3), 93-109.

Hou, Y., Lunsford, R.S., Sides, K.C., \& Jones, K.A. (2011). State Performance-Based budgeting in boom and bust years: An analytical framework and survey of the states. Public Administration Review, 71(3), 370-388.

Imbeau, L.M. (Ed.). (2009). Do they walk like they talk? Speech and action in policy processes. Dordrecht: Springer.

Ingraham, P.W. (2005). Performance: Promises to keep and miles to go. Public Administration Review, 65(4), 390-395.

Johnson, C., \& Talbot, C. (2008). UK parliamentary scrutiny of public service agreements: A challenge too far? In W. Van Dooren (Ed.), Performance information in the public sector (pp. 140-156). Dordrecht: Springer. 
Jong, M. de, Beek, I. van, \& Posthumus, R. (2013). Introducing accountable budgeting. OECD Journal on Budgeting, 12(3), 1-34.

Keulen, S. (2014). Monumenten van beleid: De wisselwerking tussen Nederlands rijksoverheidsbeleid, sociale wetenschappen en politieke cultuur, 1945-2002. Hilversum: Verloren.

Mauro, S.G., Cinquini, L., \& Grossi, G. (2017). Insights into performance-based budgeting in the public sector: A literature review and a research agenda. Public Management Review, 19(7), 911-931.

Moynihan, D.P. (2016). Political use of performance data. Public Money \& Management, 36(7), 479-481.

Moynihan, D.P., \& Pandey, S.K. (2010). The big question for performance management: Why do managers use performance information? Journal of Public Administration Research and Theory, 20(4), 849-866.

Murre, J.M., \& Dros, J. (2015). Replication and analysis of Ebbinghaus' forgetting curve. PloS One, 10(7), e0120644.

Nielsen, P.A. (2014). Learning from performance feedback: Performance information, aspiration levels, and managerial priorities. Public Administration, 92(1), 142-160.

Nispen tot Pannerden, F. van, \& Posseth, J. (2006). Performance budgeting in the Netherlands: Beyond arithmetic. OECD Journal on Budgeting, 6(4), 1-27.

Pollitt, C. (2005). Performance management in practice: A comparative study of executive agencies. Journal of Public Administration Research and Theory, 16(1), 25-44.

Pollitt, C. (2006). Performance information for democracy: The missing link? Evaluation, 12(1), 38-55.

Raudla, R. (2012). The use of performance information in budgetary decision-making by legislators: Is Estonia any different? Public Administration, 90(4), 1000-1015.

Ringe, N. (2005). Government-opposition dynamics in the European Union: The Santer commission resignation crisis. European Journal of Political Research, 44(5), 671-696.

Sterck, M. (2007). The impact of performance budgeting on the role of the legislature: A four-country study. International Review of Administrative Sciences, 73(2), 189-203.

Tweede Kamer. (2009). Dechargeverlening (achtergrondnotitie). 09-BOR-N-040 / 09-RUN-006 (14 april 2009).

Tweede Kamer, Staat van de Kamer 2010, 2015, 2017. In: Kamerstukken II 2010/11, 32 745, nr. 4; 2015/16, 34 444, nr. 4; 2018/19, 34 892, nr. 3, bijlage.

Van Dooren, W. (2004). Supply and demand of policy indicators. Public Management Review, 6(4), 511-530.

Van Dooren, W., Bouckaert, G., \& Halligan, J. (2015). Performance management in the public sector. London: Routledge.

Wit Wijnen, P. de. (2015, 29 augustus). VVD'er geeft Tweede Kamer boekhoudles. NRC Handelsblad. 